\title{
PARENTALIDADES "IMPENSÁVEIS": PAIS/MÃES HOMOSSEXUAIS, TRAVESTIS E TRANSEXUAIS
}

\author{
Elizabeth Zambrano \\ Universidade Federal do Rio Grande do Sul - Brasil
}

Resumo: $O$ aumento do número de famílias formadas por pais/mães homossexuais, travestis e transexuais tem se tornado não apenas um fato social, como também um fato socioantropológico, requerendo uma revisão das nossas conviç̧ões tradicionais. O propósito deste artigo é demonstrar como o modelo tradicional da família considerada uma família "normal" - tem influenciado a construção de parentalidades consideradas, até recentemente, impensáveis, seja socialmente ou perante a lei. $O$ desafio deste momento é enfrentar as novas demandas e desconstruir antigas certezas da antropologia, da psicologia/psicanálise e do direito, favorecendo a legitimação dessas famílias dentro da sociedade.

Palavras-chave: família, homossexualidade, parentalidade, sexualidade.

Abstract: The rising number of families formed by homosexual, transvestites and transsexual fathers/mothers has become, not only a social fact, but also a socioanthropological one, requiring a mandatory review of traditional convictions. The purpose of the present paper is to demonstrate how a traditional model of family considered a "normal" family - has been is to able to influence the construction of parenthoods considered, until recently unthinkable, either socially or in the law. Therefore, I suggest it is time to face the new demands and deconstruct former certainties of Anthropology, of Psicology/Psicanalisis and of the Law, for the sake of the families.

Keywords: family, homosexuality, parenthood, sexuality.

\section{Introdução}

A emergência de famílias constituídas por pais/mães homossexuais, travestis e transexuais no campo social torna obrigatório o enfrentamento de no- 
vas demandas e a desconstrução de velhas certezas, tanto para a antropologia quanto para a psicologia/psicanálise e para o direito.

As questões que essa parentalidade (homossexual, travesti e transexual) coloca para a antropologia atingem um dos campos de estudo mais tradicionais da disciplina, o da família e do parentesco. Também a psicanálise necessita enfrentar e colocar essas possibilidades dentro do seu corpo teórico, relativizando a idéia de serem a subjetivação e a construção do simbólico dependentes da diferença dos sexos. Da mesma maneira, o direito se vê impelido a acompanhar essas configurações criando novas possibilidades legais de conjugalidade e filiação de forma a não deixá-las à margem da proteção do Estado.

A condenação generalizada da homossexualidade que persiste nas sociedades contemporâneas, ainda muito influenciadas pela lei religiosa é, segundo Danièle Hervieu-Léger (2003), a principal resistência à visibilidade dessas famílias, percebidas como atentatórias ao caráter "sagrado" adquirido pela "família" nas sociedades modernas.

Essa "sacralidade", que toma como apoio a ordem natural das relações entre os sexos, torna "impensável” qualquer outra configuração de família que não seja a composta por pai-homem, mãe-mulher e filhos. A autora alerta, entretanto, que esse impositivo “divino” não está presente apenas nas religiões, encontra-se, também, em outras áreas do saber.

A influência religiosa se expressa nos três campos mencionados. No direito, temos o código napoleônico que mantém vivo, depois da Igreja, o caráter "sagrado" estabelecido pela "natureza” entre aliança e filiação, com a afirmação de que o pai é o marido da mãe. Para a psicanálise, a subjetivação do sujeito e sua humanização passam pela necessidade de elaboração do chamado complexo de Édipo, processo psíquico que exige a presença dos dois sexos e a obediência ao "Nom du Père”. ${ }^{1}$ Essa mesma ordem simbólica da diferença dos sexos pode ser encontrada na antropologia com a idéia de serem a proibição do incesto e a "troca de mulheres” responsáveis pela passagem da humanidade da natureza para a cultura, segundo o pensamento estruturalista de Lévi-Strauss e Françoise Héritier.

A transformação da família humana nessa "sagrada família", como lugar único e exclusivo da sexualidade e procriação legítimas, desconsidera o fato de

\footnotetext{
${ }^{1} \mathrm{O}$ uso da expressão "Nom du Père” foi estabelecido por Lacan e faz um trocadilho, em francês, indicando que a "lei" se insere no psiquismo, simultaneamente, através do "nome do pai" e do "não do pai", fazendo a interdição necessária para a humanização do sujeito e sua entrada na "ordem simbólica".
}

Horizontes Antropológicos, Porto Alegre, ano 12, n. 26, p. 123-147, jul./dez. 2006 
que ela é, apenas, uma construção histórica que se impôs ao Ocidente muito recentemente (Hervieu-Léger, 2003).

O objetivo deste trabalho é analisar as relações entre esses três domínios e evidenciar como essa concepção de família é capaz de influenciar a construção de parentalidades consideradas, até então, impensáveis, tanto social quanto juridicamente, por serem estabelecidas por pessoas do mesmo sexo. Os dados empíricos que dão suporte à essas reflexões são oriundos do projeto O Direito à Homoparentalidade, realizado em Porto Alegre entre os anos de 2004 e 2005, sob a minha coordenação (Zambrano, 2006).

\section{Algumas consideracões sobre a família ocidental contemporânea}

Na nossa sociedade contemporânea ocidental, a família é percebida como a mais "natural" das instituições, o núcleo organizador a partir do qual irão estruturar-se e serão transmitidos os valores mais importantes da nossa cultura. Essa "naturalidade" remete, como conseqüência, à idéia de universalidade. Entretanto, a definição de família, assim como a sua universalidade, não é um consenso entre os estudiosos do tema (Cadoret, 2002; Stephens, 2003). A maioria dos antropólogos concorda que uma instituição chamada "família" é encontrada em praticamente todas as sociedades, mas sua configuração é tão variada que a sua universalidade estaria condicionada à forma como for definida. Segundo Nadaud (2002) colocar a família como uma entidade única e constante no tempo pode ser mais um prejulgamento, baseado na nossa experiência pessoal, do que uma realidade.

No Ocidente, o modelo familiar mais comum corresponde ao da "família nuclear”: um pai, uma mãe e filhos. Ele está apoiado em uma realidade biológica irredutível até esse momento: é necessário um homem e uma mulher para produzir uma criança. Como conseqüência, a família nuclear procriativa parece se impor como uma verdade incontestável, justamente por estar socialmente de acordo com o fato biológico. Daí ser tão fácil pensarmos que ela tem suas raízes no início dos tempos, considerá-la como sendo a unidade fundadora da sociedade, a célula germinativa da civilização e o suporte para a evolução da sociedade (Freud, 1973).

Porém, se pensarmos nas diferentes formas de expressão da família, observaremos que existem variações temporais, espaciais e em uma mesma época e local. Em decorrência disso, seria preciso ter clara a diferença que existe entre uma noção geral de família, de um lado, e suas diferentes manifestações, 
de outro. Estudos históricos e antropológicos (Ariés, 1981; Donzelot, 1986, entre outros) demonstram que a instituição "família" vem sofrendo muitas mudanças ao longo do tempo, passando a ser o local privilegiado da afetividade, uma das características da família nuclear, apenas no século XIX.

A "naturalização" desse modelo de família torna-o incontestável e leva ao pensamento, comum na nossa cultura, de que uma criança pode ter apenas um pai e uma mãe, juntando na mesma pessoa o fato biológico da procriação, o parentesco, a filiação e os cuidados de criação. Isso acontece porque, ao percebermos "pai” e "mãe” apenas como aqueles que dão a vida à criança, concebemos essa relação como tão "natural" que nem pensamos possa ser ela submetida à lei social.

Entretanto, o vínculo familiar ligando um adulto a uma criança pode ser desdobrado em quatro elementos que nem sempre são concomitantes: 1) o vínculo biológico, dado pela concepção e origem genética; 2) o parentesco, vínculo que une dois indivíduos em relação a uma genealogia, determinando o seu pertencimento a um grupo; 3 ) a filiação, reconhecimento jurídico desse pertencimento de acordo com as leis sociais do grupo em questão; 4) a parentalidade, o exercício da função parental, implicando cuidados com alimentação, vestuário, educação, saúde, etc., que se tecem no cotidiano em torno do parentesco. Esses elementos podem estar combinados entre si de maneiras diversas, dependendo de como é estabelecido o peso de cada um em relação aos outros, evidenciando a relatividade das escolhas feitas por uma determinada cultura em uma determinada época.

A diversidade das configurações familiares de outras sociedades permite afirmar que parentesco e filiação são sempre sociais (Héritier, 2000) e não apenas derivados da procriação, já que as regras adotadas por elas não são sempre a réplica exata da "natureza”. É preciso lembrar que “embora seja exato que as regras relativas à filiação tenham por objetivo institucionalizar a reprodução da espécie humana, essa institucionalização se efetua segundo critérios que variam de uma sociedade a outra e de uma época a outra" (Gross et al., 2005, p. 31, tradução minha).

Devido a essa variação dos papéis sociais parentais desempenhados nas diferentes culturas e períodos históricos, podemos, também, compreender que parentalidade não é sinônimo de parentesco e filiação e pode ser exercida por pessoa sem vínculo legal ou de consangüinidade com a criança como ocorre, por exemplo, nas famílias recompostas, nas quais o cônjuge do pai ou da mãe participa cotidianamente da criação do filho. 
Na nossa cultura, devido ao grande valor dado aos aspectos biológicos do parentesco, esses são considerados os formadores dos vínculos familiares mais "verdadeiros". Entretanto, depois do advento das novas tecnologias reprodutivas, quando se podem separar artificialmente os momentos naturalmente indivisíveis da fabricação de um ser humano: a fecundação, a gestação e o parto, até a "verdade” biológica incontestável da maternidade pode ser questionada (Godelier, 2005). São as regras estabelecidas socialmente em cada lugar que determinam a "verdade" do parentesco, confirmando as afirmações de diversos antropólogos de que o parentesco é fundamentalmente um universo de vínculos genealógicos, simultaneamente biológicos e sociais (Cadoret, 2002; Godelier, 2005; Héritier, 2000). Não existindo um a priori de "verdadeira mãe” ou "verdadeiro pai”, apenas uma decisão moral e social determinará a quais elementos da noção de família se dará prioridade em uma determinada sociedade (Parseval, 1998).

Lévi-Strauss (1976) também apontou que a família não é uma entidade em si nem, tampouco, uma entidade fixa, ela é, antes, o lugar onde se desenvolvem as normas de filiação e de parentesco, construindo sistemas elementares cuja finalidade é ligar os indivíduos entre eles e à sociedade. São os vínculos entre os indivíduos que criam a família e são as variações possíveis desses vínculos intrafamiliares que caracterizam as formas possíveis de família.

Embora seja a mais comum entre nós, a família nuclear, monogâmica, heterossexual e com finalidade procriativa não é a única na nossa sociedade ocidental. Depois do advento do divórcio, houve uma multiplicação de novos arranjos familiares permitindo aos indivíduos a construção de novos tipos de alianças, como as famílias de acolhimento, recompostas e monoparentais.

\section{As famílias cujos pais/mães são homossexuais, travestis e transexuais}

É dentro desses novos arranjos que surge a “família homoparental”, 2 propondo um modelo alternativo, no qual o vínculo afetivo se dá entre pessoas do mesmo sexo incluindo, também, os casos da parentalidade de travestis e transexuais. Tais uniões não possuem capacidade procriativa (no sentido biológico), embora seus componentes possam tê-la individualmente.

\footnotetext{
2 Homoparentalidade é um neologismo criado em 1997 pela Associação de Pais e Futuros Pais Gays e Lésbicas (APGL), em Paris, nomeando a situação na qual pelo menos um adulto que se autodesigna homossexual é (ou pretende ser) pai ou mãe de, no mínimo, uma criança.
}

Horizontes Antropológicos, Porto Alegre, ano 12, n. 26, p. 123-147, jul./dez. 2006 
O uso do termo "família homoparental" costuma ser objeto de muitos questionamentos, pois coloca o acento na “orientação sexual” (homoerótica) dos pais/mães e a associa ao cuidado dos filhos (parentalidade). Essa associação (homossexualidade dos pais/mães e cuidado com os filhos) é, justamente, o que os estudos sobre homoparentalidade se propõem a desfazer, demonstrando que homens e mulheres homossexuais podem ser ou não bons pais/mães, da mesma forma como homens e mulheres heterossexuais. ${ }^{3}$ Os estudos demonstram que é a capacidade de cuidar e a qualidade do relacionamento com os filhos o determinante da boa parentalidade, e não a orientação sexual dos pais.

Entretanto, o seu emprego é estratégico e se justifica pela necessidade de colocar em evidência uma situação cada vez mais presente na sociedade atual. Ao nomear um tipo de família até então sem nome, permite-se que ela adquira uma existência discursiva, indispensável para indicar uma realidade, possibilitando o seu estudo e, principalmente, sua problematização (De Singly, 2000). Favorece, ao mesmo tempo, a emergência de um campo de luta político onde as demandas de (homo)parentalidade ficam fortalecidas.

Por outro lado, o conceito de "homoparentalidade" torna-se insuficiente quando se trata da parentalidade exercida por travestis e transexuais. Isso porque, da forma como foi concebido, o termo "homoparentalidade" se refere apenas à orientação sexual, aludindo às pessoas cujo desejo sexual é orientado para outras do mesmo sexo, o que deixaria de fora as pessoas com mudança de sexo (transexuais) e de gênero (travestis). Embora sejam comumente percebidas como fazendo parte do mesmo universo homossexual, travestis e transexuais apresentam especificidades na sua construção identitária e, conseqüentemente, na sua relação de parentalidade. ${ }^{4}$ As transexuais e algumas travestis se sentem e se consideram "mulheres”, mesmo tendo nascido homens biológicos.

\footnotetext{
3 Utilizamos os termos "homossexual/homossexualidade", criados pela psiquiatria como uma entidade clínica para se referir às “pessoas que fazem sexo com pessoas do mesmo sexo”, considerando que a sua existência não está vinculada a uma “essência” identitária.

4 Desde uma perspectiva antropológica, a identidade é uma ferramenta conceitual cuja característica é ser relacional e ter a propriedade de estabelecer conexões e separações entre um indivíduo e outro. Ela se constrói tanto do ponto de vista do sujeito quanto do observador. Não possui estabilidade essencial, sendo mais um percurso e um deslocamento, construtores de um sujeito em constante processo de formação. Segundo Lévi-Strauss (1995, p. 344), a identidade poderia ser considerada como um foco virtual, acionado em diferentes momentos, indispensável para servir de referência e para explicar muitas coisas, mas sem ter, verdadeiramente, uma existência real. Assim, não olhamos essas diferentes identidades como tendo existência concreta, o que reduziria em muito suas inúmeras possibilidades.
}

Horizontes Antropológicos, Porto Alegre, ano 12, n. 26, p. 123-147, jul./dez. 2006 
Para elas, é o sexo/gênero transformado que conta para sua classificação como "mulheres". Desse modo, as travestis e transexuais se consideram "mulheres" e mantém relações sexuais com homens, percebidas por elas como heterossexuais e não homossexuais. Da mesma forma, quando constroem uma relação de parentalidade, na maioria das vezes, o fazem ocupando o lugar "materno" e não "paterno", como veremos adiante. Nesses casos, fica evidente a insuficiência das categorias binárias para classificar as identidades e a sexualidade das travestis e transexuais.

Porém, embora reconhecendo a singularidade de tais situações, para a finalidade deste trabalho, ao falarmos em "homoparentalidade", estaremos entendendo que o termo abarca todas essas "identidades" dos pais, considerando que, para as travestis, o acento identitário será dado ao gênero, para as transexuais, ao sexo e para os homossexuais, à orientação.

Mesmo assim, essa configuração familiar parece ainda estar à margem do conceito de família usado por alguns operadores do direito, por mais elástico que ele possa ser atualmente. Exemplo disso são as decisões do judiciário no referente aos direitos dos casais homossexuais, com alguns juízes reconhecendo, e outros não, a união homossexual como uma entidade familiar. No Rio Grande do Sul, o desembargador José Carlos Teixeira Giorgis proferiu uma decisão pioneira no reconhecimento dessa relação como entidade familiar (TJRS, 2001). ${ }^{5}$ Também no Rio Grande do Sul a desembargadora Maria Berenice Dias (2001) trata da questão enfatizando a união homossexual como baseada em laços de afeto, sendo incluída no direito de família, enquanto Roger Rios $(2001,2002)$ a discute do ponto de vista dos direitos humanos, o que coloca a questão sob a tutela dos direitos constitucionais, no princípio da igualdade e da não-discriminação.

Recusar chamar de "família" esses arranjos, negar a existência de um vínculo intrafamiliar entre os seus membros (ainda que esses vínculos possam ter um aspecto extremamente polimorfo e variado) e impedir que tenham um estatuto legal, significa "fixar" a família dentro de um formato único, que não corresponde à diversidade de expressões adotadas por ela nas sociedades contemporâneas.

Isso acontece, em grande parte, devido à influência da psicanálise como campo legítimo de saber nas questões envolvendo a sexualidade.

5 Ver também Giorgis (2002). 


\section{A influência da psicanálise}

A maior parte das considerações utilizadas pelos diferentes profissionais (juristas, operadores do direito, psiquiatras, psicólogos e assistentes sociais) sobre a homoparentalidade está apoiada nos princípios teóricos da psicanálise. Dentro dela encontramos posições muito divergentes a respeito da homoparentalidade, não havendo evidência empírica do acerto de uma ou de outra opinião. Tais opiniões tampouco estão conectadas a uma especialidade ou corrente da psicanálise que as fundamente teoricamente. Além disso, muitos psicanalistas preferem não falar sobre o tema, pois consideram que seu papel é exclusivamente da ordem do individual, não tendo legitimidade, nem clínica nem teórica, para emitir parecer sobre questões sociais. Entretanto, a psicanálise é uma das disciplinas mais solicitadas pela sociedade para o debate sobre as novas configurações familiares, interferindo, dessa forma, no campo da ação política. Esse apelo à psicanálise funciona, na maioria das vezes, como um chamado à ordem, mais explicitamente à “ordem simbólica”, terreno sobre o qual se construiu a teoria psicanalítica.

A influência das formulações teóricas da psicanálise fica evidente nos debates ocorridos na França nos anos anteriores à criação do Pacs. ${ }^{6}$ Além das questões referentes à conjugalidade, foram abordadas as possibilidades da adoção e utilização das novas tecnologias reprodutivas pelos homossexuais, o que acabou por se tornar o foco central das discussões. Entre os profissionais do “campo psi” (psicologia, psiquiatria, psicanálise) que se manifestaram publicamente sobre o tema (e ainda se manifestam atualmente), principalmente na França, Mehl (2003) identifica três correntes de pensamento.

A primeira é contrária ao reconhecimento do casal e da parentalidade homossexual pela sociedade e pela legislação. Misturando religião e psicanálise, considera a homossexualidade uma questão privada e uma perversão e, por isso, não merecedora de reconhecimento legal. Esse discurso, mais conservador, utiliza argumentos que atuam em defesa da família tradicional e se apóiam nas tradições e crenças religiosas, embora se apresentem revestidas de um vocabulário psicanalítico ou psicológico. ${ }^{7}$

\footnotetext{
${ }^{6}$ Pacs é o Pacto de Solidariedade Civil aprovado em novembro de 1999 na França visando regulamentar as uniões entre pessoas do mesmo sexo.

7 Tem, como principais representantes, Tony Anatrela (padre e psicanalista) e Pierre Legendre (jurista e psicanalista).
} 
A segunda corrente não opina sobre o casal e a homossexualidade, mas se opõe à homoparentalidade sob o argumento de que a diferença dos sexos está no núcleo das representações identitárias, afirmando ser impossível para as crianças imaginar que possam ter sido concebidas fora dessa diferença. Em decorrência disso, a criação de crianças por pessoas do mesmo sexo seria uma destruição dos fundamentos antropológicos da constituição do parentesco, da família e da procriação. Partem do pressuposto de que os homossexuais negam a diferença dos sexos e não permitem aos filhos um contato adequado com 0 sexo oposto, o que é uma afirmação sem fundamento empírico. ${ }^{8}$

A última das correntes é composta por pessoas contrárias à utilização de um saber psicológico e psicanalítico para se posicionar contra novas formas de experimentação familiar. Consideram não caber aos psicanalistas fazerem julgamentos morais a respeito de tipos de famílias já existentes na nossa sociedade, sendo preciso reconhecer as novas formas de família, em favor de uma pluralidade de organizações contemporâneas. O argumento teórico utilizado por essa corrente para refutar a importância da diferença dos sexos dos pais para o bom desenvolvimento da criança diz que a identidade não se restringe apenas à identidade sexual e que a percepção do outro, a alteridade, não está baseada apenas na diferença do sexo. Argumentam, também, que as normas mudam, têm uma história, e seu conteúdo varia de acordo com o tempo e o lugar, não podendo ser fixadas pelas posições ideológicas do momento, em flagrante desrespeito aos resultados das pesquisas, às normas democráticas e aos direitos humanos. ${ }^{9}$

Torna-se evidente, a partir dos posicionamentos acima, quais são os principais argumentos utilizados nas discussões: a ameaça de destruição da sociedade e os prováveis prejuízos causados às crianças pertencentes à famílias homoparentais. Sustentando ambos, está a necessidade da diferença dos sexos.

Apesar desses temores e opiniões, cabe ressaltar que as famílias homoparentais já existem há muito tempo na realidade social, como demonstram os estudos e as pesquisas feitas sobre elas há 30 anos, faltando apenas o seu reconhecimento legal. ${ }^{10}$ Atualmente, estão adquirindo maior visibilidade

${ }^{8}$ O psicanalista Jean Pierre Winter é seu principal porta-voz.

9 Tem, como porta-voz, Michel Tort (psicanalista), Sabine Prokhoris (filósofa e psicanalista), Geneviève Delaisi de Parseval (psicanalista e antropóloga) e, mais tardiamente, Elizabeth Roudinesco (psicanalista e historiadora da psicanálise).

${ }^{10}$ Um levantamento dessas pesquisas pode ser encontrado em Zambrano (2006).

Horizontes Antropológicos, Porto Alegre, ano 12, n. 26, p. 123-147, jul./dez. 2006 
através da mídia, em grande parte como conseqüência da atuação dos grupos que lutam pelos direitos dos homossexuais e pelos direitos humanos.

\section{Como homossexuais, travestis e transexuais podem exercer a parentalidade}

Estão descritas na literatura quatro formas principais de acesso à homoparentalidade. A primeira delas é por filhos havidos em uma ligação heterossexual anterior. Depois do rompimento da união, o pai ou a mãe (ou ambos) podem estabelecer uma relação com parceiro/a do mesmo sexo, constituindo assim uma nova família. A nova configuração será considerada um tipo de família recomposta, cuja especificidade é o contexto homoparental.

A segunda maneira é pela adoção, podendo ser legal ou informal. Atualmente, a adoção legal por homossexuais é buscada, na maioria das vezes, individualmente. Existe o temor da recusa se o pedido for feito pelo casal, quando ficaria explicitada a homossexualidade. A adoção legal implica o estabelecimento de um vínculo de filiação irrevogável, unindo o adulto adotante e a criança adotada, com os direitos e deveres daí decorrentes. Quando a adoção é informal, não estabelece vinculação legal entre os participantes, apenas vínculos afetivos, sem os direitos de filiação. Podemos considerar também a chamada "adoção à brasileira”, quando um adulto registra como sendo seu filho biológico o filho de outra pessoa.

Uma terceira forma é a busca de filhos pelo uso de novas tecnologias reprodutivas, possibilitando o nascimento de filhos biológicos. O método mais utilizado pelas mulheres lésbicas é a inseminação artificial ou fertilização medicamente assistida. Pode ser com doador conhecido, geralmente um amigo gay, ou doador desconhecido, através de um banco de esperma. Os homens gays que quiserem filho biológico sem relação sexual com uma mulher têm de fazer uso da "barriga de aluguel”, procedimento considerado ilegal no Brasil. Nesses casos, se for cumprido o anteriormente combinado com o pai, a mãe entregará a ele o filho recém-nascido e abrirá mão dos direitos e vínculos legais com a criança.

Finalmente, a quarta possibilidade é a chamada co-parentalidade, na qual os cuidados cotidianos são exercidos de forma conjunta e igualitária pelos parceiros, podendo aparecer entrelaçada com as formas de acesso citadas anteriormente. A parceria pode dar-se pelo planejamento conjunto do casal homossexual, no qual os parceiros decidem pela adoção de uma criança ou pelo uso de novas tecnologias reprodutivas para formar uma família, sendo a parentalidade, 
desde o início, exercida igualmente pelos dois, mesmo que apenas um deles seja o pai biológico ou legal. Em outros casos, pode ser uma parentalidade exercida conjuntamente pelo companheiro/a do pai/mãe legal de um filho nascido antes da relação de parceria como, por exemplo, na situação muito comentada na mídia, vivida por Eugênia, parceira da cantora Cássia Eller. O planejamento conjunto pode, também, incluir dois casais homossexuais, um masculino e o outro feminino, que decidem ter um filho através de inseminação artificial caseira (coleta de sêmen do pai e introdução do esperma na vagina da mãe, com o auxílio de uma seringa, sem a presença do médico) ou medicamente assistida (feita em clínica médica especializada). Nesse caso, a criança terá dois pais e duas mães, sendo dois deles pai e mãe biológicos.

Em pesquisa antropológica realizada em Porto Alegre sob a minha coordenação e que tomou como ponto de partida as representações de parentalidade de indivíduos nascidos homens biológicos (homens homossexuais, homens travestis e transexuais homem para mulher), a forma de acesso ao projeto parental preferida pela totalidade dos entrevistados é a adoção. Nenhum deles utilizou ou planeja utilizar tecnologias reprodutivas, mostrando que a parentalidade social é, para eles, mais importante do que os laços biológicos. $\mathrm{O}$ fato de nossos entrevistados serem homens biológicos faz com que tenham pouca autonomia corporal para chegar à parentalidade, precisando de um corpo feminino para dar seguimento à gestação. Para as mulheres essa autonomia é maior, pois podem obter o esperma em bancos de esperma e dar seguimento à gestação sem necessidade de um homem. Como conseqüência, a busca desse tipo de paternidade biológica para os homens gays acaba se tornando menos prioritária. Essa tendência dos nossos entrevistados está de acordo com os dados obtidos no Brasil sobre homoparentalidade, indicando que a valorização da parentalidade biológica é mais importante entre as mulheres. ${ }^{11}$

\footnotetext{
11 Tarnovski (2003), em sua pesquisa realizada com homens que se identificavam como gays, em Florianópolis, refere que existe pouca demanda de novas tecnologias reprodutivas por parte de homens, sendo a adoção formal ou informal a forma de acesso à parentalidade mais procurada. Uziel (2002) mostra que a maior incidência de pedidos de adoção, no Rio de Janeiro, é feita por homens. Dos oito casos analisados por ela, apenas um era apresentado por mulher. Os dados de Eugênio (2003) apontam uma demanda maior de inseminação artificial por mulheres lésbicas, em seus projetos parentais. Sousa (2005) relata que, no Canadá, prevalece a busca de novas tecnologias por mulheres lésbicas, enquanto no Brasil, a maioria das famílias lésbicas estudadas pela autora é composta pela incorporação dos filhos de relacionamentos heterossexuais anteriores.
}

Horizontes Antropológicos, Porto Alegre, ano 12, n. 26, p. 123-147, jul./dez. 2006 
Nas famílias de travestis e transexuais, o acesso à parentalidade se dá, em geral, pela adoção informal de crianças, oriundas de familiares, amigos, vizinhos ou, simplesmente, qualquer criança abandonada. Esse modo informal de circulação de crianças é uma característica das classes populares brasileiras, conforme mostrado por Fonseca (2002). Comumente, essa parentalidade acontece devido a uma situação casual. A adoção informal, desse modo, resulta de uma conjunção entre o desejo de ter filhos e o compadecimento em relação à situação de abandono das crianças. Mais do que pena, a criança abandonada desperta uma identificação com a sua trajetória pessoal de preconceito e abandono.

Quando perguntadas sobre as preferências por sexo ou raça das crianças, elas tendem a responder que "tanto faz". ${ }^{12}$ Algumas informantes dizem, inclusive, que nem iriam se importar se a criança não fosse "perfeitinha", aceitariam e criariam com muito amor a criança mesmo que "faltasse um pedacinho". Assim, elas geralmente recorrem ao poder judiciário apenas para pedir a guarda da criança de que já cuidam.

O recorte de classe torna-se obrigatório para a compreensão do modo escolhido pelas travestis e transexuais para chegar à parentalidade. Além da escolaridade (apenas uma das oito informantes completou o primeiro grau) pesa, também, a profissão das entrevistadas que, com exceção de uma, são ou foram profissionais do sexo. A baixa escolaridade e o tipo de profissão - objetos de restrições por parte das instituições oficiais - dificultam não apenas a possibilidade de adoção e guarda, mas, também, o acesso aos meios para lutar por ela.

A mudança nos documentos de identidade é, para as transexuais, de enorme importância para o acesso à parentalidade, pois é pelo uso de documentos adequados à sua identidade social que pensam conseguir a adoção legal de uma criança. Assim, algumas fazem planos de adotar legalmente, mesmo tendo presente a possibilidade de serem impedidas devido às diferentes formas do poder judiciário tratar a questão.

As travestis, porém, raramente pensam na possibilidade de acionar a via judicial para adotar, devido ao preconceito que temem sofrer quando tentarem

\footnotetext{
${ }^{12} \mathrm{O}$ uso do gênero gramatical feminino visa acompanhar o gênero reivindicado pelas travestis e transexuais.
} 
uma adoção. Como não fazem a cirurgia de transgenitalização, dificilmente conseguem trocar os documentos, o que, junto com a classe social (popular), a escolaridade (baixa) e a profissão (prostituição), torna muito pouco provável o deferimento de um pedido de adoção. Como diz uma informante: "Se para os heterossexuais já é complicado adotar, imagina pra nós travestis que já sofremos tanto preconceito.”

As análises sociológicas mais recentes salientam o papel do estigma na produção e reprodução das relações de poder e controle dos sistemas sociais, fazendo alguns grupos sentirem-se desvalorizados e outros superiores. Foucault (1988) já demonstrou que as formas de elite de conhecimento, entre elas a psicanálise/psiquiatria, ajudam a constituir diferenças nas sociedades modernas, sinalizando-as e criando categorias diferentes de pessoas. O poder/saber é usado para legitimar essas diferenças. Assim, as pessoas estigmatizadas e discriminadas aceitam e internalizam o estigma por estarem sujeitas a um aparato simbólico opressivo cuja função é legitimar essa desigualdade. Segundo Parker e Aggleton (2002), os indivíduos estigmatizados ficam com pouca capacidade de reação. Essa disposição pode ser evidenciada na fala citada acima, cujo argumento perpassa muitas das outras entrevistas.

\section{Como são vivenciados os papéis de gênero}

O questionamento freqüente sobre quem será o pai e quem será a mãe numa família homoparental é uma artificialidade que desconsidera o fato de que um homem gay não se torna mulher por ter o seu desejo sexual orientado para um outro homem, assim como uma mulher lésbica não se torna homem pela mesma razão. Se pensarmos em termos de "função parental”, podemos dizer que a função "materna” ou "paterna” poderá ser desempenhada por qualquer dos parceiros, mesmo quando exercida de forma mais marcante por um ou outro dos membros do casal, sem que isso os transforme em mulher ou homem.

Do ponto de vista da psicanálise, considera-se necessária a presença de um “terceiro" para a separação psíquica entre mãe e filho, uma das atribuições da chamada "função paterna". Entretanto, nas discussões sobre famílias nas quais os pais são do mesmo sexo, há uma confusão entre o entendimento do que seja a função psíquica cumprida pelo "terceiro" e a sua nomeação como "paterna”. Tanto nos casais gays quanto lésbicos, a função de "terceiro" pode 
ser exercida pelo parceiro/a do pai/mãe. Ao ser ele/ela o "objeto de desejo" do pai/mãe, introduz-se na fusão mãe-filho inicial, mostrando ao filho a existência de um "outro" desejado e, com isso, inaugura a alteridade. Para o filho, não importa o sexo da pessoa para a qual o desejo do pai/mãe está direcionado. O importante é a descoberta da existência de uma outra pessoa, que não ele/ela, por quem o pai/mãe sente desejo. A manutenção da idéia de que o "terceiro" teria que ser o pai-homem promove um deslizamento do simbólico para o real, evidenciando o vínculo que a psicanálise sustenta com a manutenção de uma “ordem familiar" patriarcal.

Entre o nossos informantes, usualmente, o exercício das funções materna e paterna se dá de acordo com as características e preferências de cada um, não havendo necessariamente, nos casais homossexuais, uma divisão rígida de "papel de gênero": feminino para o que cumpre uma função dita materna e masculino para uma função dita paterna. Um dos dois pode exercer mais o papel de autoridade, normalmente aquele considerado o "verdadeiro" pai, por ser o pai biológico ou por ser o pai adotante, o único reconhecido pela lei. O segundo pai ou o companheiro do pai, em geral, ocupa um lugar mais "maternal”, não porque seja mais feminino na sua identidade, mas porque se encarrega das tarefas nas quais o reconhecimento do "verdadeiro" ou do legal não é solicitado, geralmente os cuidados domésticos. Nas famílias em que um dos componentes é travesti ou transexual, a divisão dos papéis parentais é mais definida e parece se dar de acordo com o sexo/gênero de "escolha" de cada um: mulheres transexuais e travestis são consideradas mães e seus companheiros, pais.

Cada grupo familiar pesquisado por nós reinventa seus próprios termos de nomeação, para possibilitar a inclusão de outros tipos de cuidadores parentais, além da nomeação tradicional "pai” e "mãe”. Encontramos nomes como "dindo", "painho" - "mainha” e equivalentes femininos para as travestis e transexuais e alguns diminutivos dos nomes próprios sendo utilizados pela criança para nomear o segundo cuidador, todos indicando a existência de uma ligação afetiva mais significativa. Por não haver uma definição, nem social nem legal, para esses outros cuidadores, não existem, ainda, termos de parentesco que permitam nomeá-los. Mesmo assim, é importante salientar que as crianças não fazem confusão sobre o gênero dos pais (os homens são chamados de pai ou equivalente e as mulheres de mãe ou equivalente) e não são prejudicadas, em termos do aprendizado das diferenças sexuais dos pais, pelo fato de serem criadas em famílias homoparentais. 
É preciso levar em conta que os casais de homens que criam filhos, dificilmente escapam da presença das mulheres no cotidiano, pois os trabalhos com a primeira infância são profundamente feminilizados. Confirmamos isso com os nossos informantes homossexuais, os quais, embora justifiquem o não-recurso às novas tecnologias reprodutivas pela idéia de não querer depender de uma mulher, em sua maioria, reconhecem a necessidade de uma pessoa do sexo feminino, durante a vida cotidiana, para ajudar nos cuidados com a criança. Essa necessidade alude ao cumprimento das tarefas domésticas e à valorização de uma mulher que sirva como modelo de "feminino" para a criança. Contam para isso com empregada, mãe, irmãs e até amigas para auxiliar no cuidado com os filhos.

Um dado que vai no mesmo sentido é o de muitos dos homossexuais entrevistados pretenderem adotar uma criança mais crescida, que não demande "cuidados especiais", para os quais as mulheres são entendidas como mais aptas. Os entrevistados demonstram querer que as crianças mantenham contato com pessoas de ambos os gêneros. Assim, o fato de ser criada por dois homens não implica que a criança crescerá sem referências femininas no seu cotidiano familiar.

Apesar da incorporação, na configuração familiar, de espaços para outros tipos de cuidadores, as representações das figuras parentais principais continuam sendo "maternas" e "paternas", às quais se atribuem diferentes tipos de cuidados parentais, dentro dos modelos de gênero tradicionais. Mesmo os casais de homens que adotam e criam o filho em conjunto, buscam figuras femininas (suas mães ou empregadas domésticas) para os cuidados cotidianos que envolvem alimentação, vestuário e saúde.

As travestis e transexuais que planejam ser mães também esperam encontrar um homem que as ajude a criar o filho. Permanece com ele o papel tradicional de pai, ficando ao encargo delas os cuidados maternos com a criança, numa representação de família que opera segundo os papéis tradicionais de gênero e parentalidade.

\section{A maternidade das travestis e transexuais}

Apesar de serem percebidas como fazendo parte de um mesmo "universo homossexual”, as travestis e as transexuais têm algumas características específicas na construção da identidade sexual e de gênero que precisam ser bem 
compreendidas para que possamos perceber com clareza as conseqüências sobre o tipo de parentalidade que possam vir a exercer.

A visão do senso comum considera que tanto travestis quanto transexuais fazem parte de um grupo mais amplo, abarcando também homossexuais. Essa categorização incorre numa confusão entre o que chamamos de "orientação" do desejo sexual (com as "práticas sexuais" correspondentes: homossexualidade, heterossexualidade, bissexualidade) e as "identidades de gênero" (a percepção de si como homem, mulher, travesti, transexual). Ambas as categorias (travestis e transexuais) identificam a si próprias como mulheres, vítimas de um "erro da natureza", tendo nascido com um corpo trocado: alma de mulher em corpo de homem. A diferença entre elas seria que, para as transexuais, segundo a medicina, haveria o aparecimento precoce do sentimento de pertencer ao outro sexo e o desejo de fazer a cirurgia de "troca de sexo".

Entretanto, existem outras diferenças que são acionadas pelas próprias travestis e transexuais na sua construção identitária. As transexuais têm a necessidade permanente de provar que a sua "alma de mulher” provém desde o nascimento, característica que as colocaria dentro do diagnóstico de "transexualismo verdadeiro" legitimando as suas demandas frente às instituições médicas e jurídicas (cirurgia de transgenitalização e troca de documentação). Esse diagnóstico também alivia o peso das acusações sociais de conduta desviante. A diferenciação reivindicada pelas transexuais em relação às travestis vem da necessidade de se separar da imagem de violência, marginalidade e prostituição comumente ligada a estas últimas. Essa conduta é uma estratégia de enfrentamento do estigma e do preconceito social contra a sua diferença. O desejo de legitimidade social está apoiado na idéia de que, por serem vítimas da natureza, o seu comportamento não implicaria nenhum tipo de desvio moral, como o atribuído socialmente à homossexualidade e ao travestismo (Zambrano, 2003).

As travestis igualmente se consideram "mulher em corpo de homem", embora não se enquadrem em todos os parâmetros diagnósticos da medicina para o transexualismo. Elas também apresentam os códigos da feminilidade, porém é a sua apresentação em excesso que confere a elas a identidade de travestis, tendo o seu glamour um sentido tanto de fantasia quanto de artifício (Cornwall, 1994).

Por se sentirem "mulheres", tanto travestis quanto transexuais consideram que as relações afetivo/sexuais com parceiros homens são hetero e não homossexuais. Com isso, os casais constituídos dessa forma são percebidos 
por elas como heterossexuais, contemplando as expectativas dos papéis de gênero intrafamiliares mais tradicionais. Pela mesma razão, a posição parental que pretendem ocupar em relação aos filhos é materna e não paterna. A sua posição de “mãe” é complementada pela posição de "pai” do companheiro.

Todavia, como o poder judiciário, apoiado nas considerações médicas, só considera possível a troca de sexo e nome nos documentos de identidade das transexuais depois da cirurgia, essas constroem expectativas diferentes das travestis no que respeita à adoção de crianças. ${ }^{13}$ Os traços que as diferenciam e os que as aproximam vão determinar a maneira como pretendem constituir uma família e criar seus filhos.

O discurso das travestis e transexuais sobre a sua capacitação para a parentalidade é o mesmo e se desenvolve no sentido de mostrar que são possuidoras de um "instinto materno". Enfatizam muito suas experiências anteriores de cuidados maternais, legitimando essa capacidade parental materna, percebida por elas como "instintiva”, com narrativas de situações nas quais, ainda na infância e na adolescência, "cuidaram” de crianças de sua família, como irmãos mais novos, sobrinhos, filhos de outros familiares, de vizinhos e amigos de suas famílias de origem.

Chodorow (1990) argumenta que o aprendizado do "cuidado com as crianças" é parte fundamental da socialização das mulheres, em nossa sociedade. É importante salientar, também, a existência de trabalhos clássicos, como o de Elisabeth Badinter (1985), contrapondo-se às teorias que postulam a existência de um "instinto materno", inato e universal, compartilhado por todas as mulheres. A autora defende que amor materno é, na verdade, um mito, que assume um valor social incalculável e exerce uma imensa coerção sobre os nossos desejos. Isso, porém, não implica ser ele universal, nem estar presente nas mulheres sob forma de um instinto.

Os nossos dados corroboram essas idéias mostrando que não é necessário ser mulher biológica para se sentir portadora de um "instinto materno". Parece-nos que, da mesma forma que a maior parte das mulheres, as travestis e transexuais entrevistadas não apenas incorporaram, através da socialização, esse “instinto” que as qualifica como "naturalmente” aptas à maternidade, mas,

\footnotetext{
${ }^{13}$ Recentemente, no dia 5 de abril de 2006, a Sétima Câmara Civil do TJRS aprovou o pedido de troca de nome na documentação para uma transexual não-operada, porém negou a troca de sexo.
}

Horizontes Antropológicos, Porto Alegre, ano 12, n. 26, p. 123-147, jul./dez. 2006 
também, por meio dele, corroboram socialmente a afirmativa de serem psiquicamente "mulheres".

Talvez por isso, a totalidade das travestis e transexuais entrevistadas declara não querer fazer uso de coleta de sêmen e de novas tecnologias reprodutivas para terem um filho biológico. Muitas reagiram de forma indignada à sugestão dessa possibilidade, remetendo a uma representação de "paternidade" associada ao uso do sêmen. Afirmam que essa alternativa seria impensável, porque ao coletar sêmen o fariam como homens, enquanto seu desejo de filhos está relacionado ao desejo de ser "mães" e não "pais". Tal maneira de encarar essa possibilidade nos remete à importância, para essas informantes, da representação da maternidade como confirmadora do seu gênero feminino. Esse dado, entretanto, não pode ser generalizado, pois o trabalho de campo relacionado a esse segmento do universo empírico ainda está em fase inicial. É possível que, em lugares onde a maternidade e a paternidade estejam relacionadas a outras representações, as novas possibilidades tecnológicas possam vir a ser utilizadas.

Entrevistamos apenas uma travesti e uma transexual com filhos provenientes de relação heterossexual anterior. Ambas evidenciam que a representação parental ligada a esses filhos continua sendo paterna, mesmo após a transformação corporal. Nesses casos, percebe-se a coexistência da representação parental masculina, construída anteriormente, e da representação parental feminina, construída na atualidade. É interessante assinalar que a representação paterna é dada pelo corpo, está ligada aos fluidos (sêmen, hormônios) produzidos anteriormente pelo corpo masculino, enquanto a representação materna é dada pelo social e está relacionada à percepção subjetiva de si como possuidora de uma "essência” feminina dentro de um corpo também feminilizado.

Constatamos a presença de diferentes investimentos dos informantes em relação aos filhos provenientes de contexto heteroparental e filhos planejados em contexto homoparental. Nesse sentido, Eugênio (2003, p. 11) sugere que se analise essa diferença a partir das categorias de "filhos memória" e "filhos projeto”, centradas na percepção de diferentes temporalidades da parentalidade, evidenciando vivências distintas. Os "filhos memória” seriam a materialização da lembrança de que os homossexuais já foram heterossexuais e as travestis e transexuais já foram homens. Desse modo, as relações com os "filhos memória” são marcadas pelas tensões da nova construção identitária desses sujeitos, as quais podem acarretar, inclusive, rupturas das relações parentais. Já os “fi- 
lhos projeto", estão sujeitos a um investimento diferenciado, porque conjugam o desejo de filhos com a consolidação da identidade sexual ou de gênero atual.

Sugerimos que, devido ao grande peso do valor "família” na nossa sociedade, a parentalidade pode ser um elemento usado para positivar a homossexualidade, o travestismo e o transexualismo, assumindo um papel importante no processo social de afastamento do estigma, o que, como conseqüência, leva a uma considerável ampliação da cidadania. ${ }^{14}$ Essa possibilidade de relativização do estigma aparece na fala de um dos operadores do direito quando diz “... uma criança infectada [pelo HIV], a mais cuidada do ambulatório, a mais paparicada, a que não tinha uma assadurinha, era cuidada por uma travesti... acho que em relação a travestis e transexuais a gente teria que repensar, estudar, desconstruir alguma coisa... ou reconstruir, não é?”

Como já referimos anteriormente, os dados coletados demonstram que, embora tenham um sexo de nascimento masculino, as travestis e transexuais podem evidenciar representações parentais femininas e maternas. Essas estão mais relacionadas aos filhos efetivos ou projetados depois das transformações corporais, indicando a maior importância da identidade de gênero do que o pertencimento ao sexo biológico, para construir essa representação. Desse modo, a parentalidade materna reforça a identidade feminina das travestis e transexuais.

\section{Repercussões sobre o campo jurídico}

A legislação brasileira não incide da mesma maneira sobre as diferentes possibilidades de existência de famílias homoparentais. A co-parentalidade, por exemplo, é uma das formas possíveis de família homoparental sobre a qual o direito não tem nenhuma ingerência na construção. O nosso Código Civil tampouco prevê a complexidade de alianças e filiações decorrentes da coparentalidade homossexual. Dessa forma, não pode garantir à criança nem a estabilidade nem a memória de seus vínculos parentais, pois, ao reconhecer a existência legal de apenas um pai e uma mãe, deixa fora da proteção do Estado os outros participantes dessa nova configuração, juntamente com os direitos e deveres que lhes são inerentes.

${ }^{14} \mathrm{O}$ trabalho de Tarnovski (2003) confirma esse dado no referente aos pais homossexuais. 
Nos casos de co-parentalidade, a criação do filho se dá de forma conjunta, pelo contrato entre duas pessoas (ou dois casais) de sexo oposto, que não mantêm entre si relação de conjugalidade. Essa modalidade inscreve a concepção num contexto heterossexual e a criação em contexto deliberadamente homossexual. Assim, os co-parentes asseguram à criança, pelo menos teoricamente, o conhecimento das origens biológicas e afetivas, mas não garantem a proteção legal das relações derivadas delas. O recurso ao uso de novas tecnologias reprodutivas também não está regulamentado pelo Código Civil brasileiro. Segundo Brauner (2003), a única normatização existente é uma resolução do Conselho Federal de Medicina, o que deixa a cargo das opiniões pessoais e posições ideológicas dos médicos o acesso ou não dessas pessoas homossexuais às novas tecnologias.

Nessas duas situações os problemas legais acontecem depois do nascimento do filho e são relativos aos direitos e deveres dos parceiros/as dos pais/ mães biológicos, que ainda não encontraram lugar nem social nem legalmente reconhecido.

Nos casos em que o contexto familiar homossexual é posterior a uma relação heterossexual desfeita, o problema legal que poderá surgir será relativo ao uso da homossexualidade de um dos pais como justificativa para impedimento do exercício do seu direito de parentalidade como guarda, visita, pernoite, férias, etc. Em outros casos, pode haver uma exigência por parte do pai/mãe heterossexual de não-convivência da criança com o novo parceiro/a do pai/ mãe homossexual, sob alegação de ser necessário proteger a criança do conhecimento desse tipo de relacionamento. Nessas situações, o impedimento constitucional de discriminação, por qualquer razão, deveria ser suficiente para evitar que os direitos parentais das pessoas homossexuais sejam desrespeitados. Entretanto, as pesquisas mostram que uma das grandes preocupações das mães lésbicas é, justamente, perder a guarda dos seus filhos devido a tal tipo de situação. Quando isso acontece, a justificativa apresentada na sentença costuma ser a defesa do melhor interesse da criança, ao ser considerada a homossexualidade do pai/mãe um fator de prejuízo para o bom desenvolvimento do filho (Julien; Dubé; Gagnon, 1994).

Quando a escolha é pela adoção, os diferentes obstáculos jurídicos à constituição de uma família adotiva homoparental decorrem, de um lado, da impossibilidade de desvincular os aspectos biológicos, sociais e jurídicos da filiação e, de outro, da norma da "diferença dos sexos”. A adoção legal é a situação na qual o poder judiciário é sempre chamado a se manifestar e, como tem por 
finalidade dar uma família a uma criança, a intenção é criar uma filiação o mais próximo possível da biológica, mesmo que a adoção seja o exemplo típico de filiação instituída pelo direito e não pela natureza (Gross, 2003). Como na homoparentalidade por adoção essa ficção jurídica não pode ser mantida, fica dificultada a adoção pelos casais homossexuais.

Embora a lei não traga impedimento à adoção por casais homossexuais, todos os nossos informantes que buscaram a adoção legal o fizeram individualmente, mesmo estando em parceria conjugal. ${ }^{15}$ Entendemos que a representação da família nuclear vigente na nossa sociedade, e muitas vezes compartilhada pelos informantes, pode trazer como implicação o temor de um indeferimento do pedido da adoção pelo fato de serem homossexuais, o que explica sua conseqüente opção por não demandar a adoção conjunta. Assim, os homossexuais entrevistados que têm ou planejam ter acesso à parentalidade, em sua maioria, optam pela adoção legal por parte de apenas um dos parceiros.

A escolha da adoção como via principal de acesso à parentalidade não pode ser pensada sem considerar as peculiaridades dos nossos informantes homossexuais, pertencentes às camadas média e média alta da população, alto nível de escolaridade, militância ou amizade com militantes de grupos que lutam pelos direitos dos homossexuais. Essas características se afirmam como significativas no fato de todos buscarem a adoção através do sistema judiciário, mesmo admitindo a possibilidade de enfrentar preconceitos. É preciso levar em conta que existe, para esses informantes, não apenas uma consciência maior dos direitos de cidadania, mas, também, recursos financeiros para lutar por eles. Para travestis e transexuais a situação é bem diferente, como vimos anteriormente.

Nos dados coletados entre os operadores do direito, pudemos observar que a preocupação maior é sempre em relação ao bem-estar da criança. Se o adotante é homossexual aumenta a apreensão quando comparado com adotantes heterossexuais. Em relação a isso, Uziel (2002) analisa que a alegação dos operadores do direito sobre uma maior avaliação das condições de adotantes homossexuais está centrada na possibilidade de a homossexualidade dos pais interferir no bem-estar da criança. Desse modo, os operadores tendem a interpretar a adoção por homossexuais como menos favorável para a criança. Em Porto Alegre, os discursos dos operadores do direito são muito cuidadosos em

${ }^{15}$ Para maior esclarecimento, ver Lorea (2005). 
relação à possibilidade de haver preconceito pela orientação sexual e não são poucas as vezes em que as avaliações das demandas dos homossexuais têm resultado positivo. Apesar disso, os questionamentos relativos à sexualidade e à capacidade parental dos pais são sempre mais profundamente pesquisados quando o demandante é percebido como gay ou lésbica.

\section{Considerações finais}

A necessidade da diferença dos sexos perpassa todos os campos de saber que, de alguma maneira, influenciam e decidem as questões da parentalidade homossexual, travesti e transexual. Tomando como base essa necessidade são construídas as idéias que questionam a sobrevivência das sociedades e a saúde mental das crianças. Esse discurso, construído histórica e culturalmente, atinge, entretanto, de forma diferente cada um dos grupos considerados.

Em relação aos homossexuais, é a própria falta da presença dos dois sexos o fator que justifica as reservas quanto à sua parentalidade. Os argumentos são de que as crianças irão crescer sem ter referências do masculino e feminino ficarão psicóticas, serão discriminadas e, ao final de tudo, serão também homossexuais, colocando em risco de desaparecimento a própria civilização.

O paradoxo é que o argumento usado para impedir a parentalidade homossexual - a falta de diferença dos sexos - é o mesmo que deveria autorizar a parentalidade transexual. Fizeram cirurgia de "troca de sexo" arrumando o "erro" da natureza, foram reconhecidas como mulher (ou homem) juridicamente, podendo, com isso, adotar legalmente (pelo menos na teoria). Além do mais, caso a parentalidade seja compartilhada com um homem, fica mantido o estatuto heterossexual da relação. A questão da diferença de sexo, necessária para a criação de filhos, está solucionada, como confirmam seus novos documentos, constando no registro nome e sexo corrigidos. Como explicar, então, a reserva contra essa parentalidade?

Com as travestis o problema é outro. Se os homossexuais ameaçam a "ordem” pelo comportamento, desejando e fazendo sexo com pessoas do mesmo sexo, as travestis ameaçam corporalmente, pois é o próprio corpo que subverte a norma. Metade homem, metade mulher, é a indefinição, a concomitância, a ambigüidade corporal relacionada à diferença sexual o que torna “impensável” a possibilidade parental.

Todas essas situações levantam questões para a antropologia, psicanálise e direito, como assinalado no presente trabalho. O grande desafio que se colo- 
ca é o de que, embora "impensáveis”, essas parentalidades são, entretanto, “vivíveis”, e estão aí obrigando essas instituições sociais e campos do saber a uma adequação urgente e condizente com a realidade atual.

\section{Referências}

ARIÉS, Philippe. História social da criança e da família. Rio de Janeiro: Guanabara, 1981.

BADINTER, Elizabeth. Um amor conquistado: o mito do amor materno. Rio de Janeiro: Nova Fronteira, 1985.

BRAUNER, Maria Claudia Crespo. Direito, sexualidade e reprodução humana: conquistas éticas e debate bioético. Rio de Janeiro: Renovar, 2003.

CADORET, Anne. Des parents comme les autres. homosexulité et parenté. Paris: Odile Jacob, 2002.

CHODOROW, Nancy. Psicanálise da maternidade: uma crítica a Freud a partir da mulher. Rio de Janeiro: Rosa dos Tempos, 1990.

CORNWALL, A. Gendered identities and gender ambiguity among travesties in Salvador, Brasil. In: CORNWALL, A.; LINDISFARME, N. Dislocating masculinity. London: Routledge, 1994. p. 111-132.

DE SINGLY, François. Débathèmes, saison 1997-1999. Paris: APGl, 2000.

DIAS, M. B. União homossexual: o preconceito e a justiça. Porto Alegre: Livraria do Advogado, 2001.

DONZELOT, Jacques. A polícia das famílias. Rio de Janeiro: Graal, 1986.

EUGÊNIO, Fernanda. De pais, mães e filhos: discursos e reivindicações da homoparentalidade. GT Homossexualidades, Política e Direitos. In: REUNIÃO DE ANTROPOLOGIA DO MERCOSUL, 5., 2003, Florianópolis. Comunicação oral.

FONSECA, Claudia. Caminhos da adoção. São Paulo: Cortez, 2002.

FOUCAULT, M. História da sexualidade I: a vontade de saber. Rio de Janeiro: Graal, 1988. 
FREUD, Sigmund. El malestar em la cultura. In: FREUD, Sigmund. Obras completas. Madrid: Biblioteca Nueva, 1973. t. 3.

GIORGIS, José Carlos Teixeira. Natureza jurídica da união homoerótica. Revista da Associação dos Juízes do RS, Porto Alegre, v. 88, t. 1, p. 224-252, dez. 2002.

GODELIER, Maurice. Métamorphoses de la parenté. Paris: Fayard, 2005. GROSS, Martine. L'Homoparentalité. Paris: Presses Universitaires de France, 2003.

GROSS, Martine et al. Homosexualité, mariage et filiation. Paris: Éditions Syllepse, 2005.

HÉRITIER, Françoise. A coxa de Júpiter. Revista Estudos Feministas, Florianópolis: CFH/UFSC, v. 8, n. 1, p. 98-114, 2000.

HERVIEU-LÉGER, Daniele. Préface. In: GROSS, Martine. L’Homoparentalité. Paris: Presses Universitaires de France, 2003. p. 5-8.

JULIEN, Danielle; DUBÉ, Monique; GAGNON, Isabelle. Le développement des enfants de parents homosexuels comparé à celui des enfants de parents hétérosexuels. Revue Québécoise de Psychologie, v. 15, n. 3, 1994. Disponível em: <http://www.france.qrd.org/assocs/apgl/>. Acesso em: 28 set. 2004.

LÉVI-STRAUSS, Claude. As estruturas elementares do parentesco. Petrópolis: Vozes, 1976.

LÉVI-STRAUSS, Claude. L'Identité. 3 ed. Paris: Quadrige, 1995.

LOREA, Roberto. Homoparentalidade por adoção no direito brasileiro. Revista Juizado da Infância e Juventude, Porto Alegre: Tribunal de Justiça do RS, ano 3, n. 5, p. 37-44, março de 2005.

MEHL, Dominique. La bonne parole: quand les psys plaident dans les médias. Paris: Éditions de la Martinière, 2003.

NADAUD, Stéphane. Homoparentalité: une nouvelle chance pour la famille? Paris: Fayard, 2002.

PARKER, R; AGGLETON, P. Estigma, discriminação e Aids. Rio de Janeiro: Abia, 2002. 
PARSEVAL, Geneviève Delaisi de. Préface. In: DUBREUIL, Eric. Des parents de même sexe. Paris: Éditions Odile Jacob, 1998. p. 11.

RIOS, Roger Raupp. A homossexualidade no direito. Porto Alegre: Livraria e Editora do Advogado, 2001.

RIOS, Roger Raupp. O princípio da igualdade e a discriminação por orientação sexual. São Paulo: Revista dos Tribunais, 2002.

SOUSA, Érica. Necessidade de filhos: maternidade, família e (homo) sexualidade. Tese (Doutorado em Ciências Sociais)-Instituto de Filosofia e Ciências Humanas da Universidade Estadual de Campinas, Campinas, 2005.

STEPHENS, Willian. La família em uma perspectiva transcultural. In: NIETO, Jose Antonio. Antropología de la sexualidad y diversidad cultural. Madrid: Talasa, 2003. p. 93-117.

TARNOVSKI, Flávio Luiz. Pais assumidos: adoção e paternidade homossexual no Brasil contemporâneo. Dissertação (Mestrado em Antropologia Social)Universidade Federal de Santa Catarina, Florianópolis, 2003.

TJRS. Sétima Câmara Cível. APC $70001388992 . j .14$ mar. 2001 (Relatório do desembargador José Carlos Teixeira Giorgis).

UZIEL, Anna Paula. Família e homossexualidade: velhas questões, novos problemas. Tese (Doutorado em Ciências Sociais)-Instituto de Filosofia e Ciências Humanas, Universidade Estadual de Campinas, Campinas, 2002.

ZAMBRANO, Elizabeth. Trocando os documentos: um estudo antropológico sobre a cirurgia de troca de sexo. Dissertação (Mestrado em Antropologia Social)-PPGAS, Universidade Federal do Rio Grande do Sul, Porto Alegre, 2003.

ZAMBRANO, Elizabeth. O direito à homoparentalidade: cartilha sobre as famílias constituídas por pais homossexuais. Porto Alegre: Vênus, 2006. 